\title{
Application of remote sensing data to assess environmental situation in Krasnoyarsk
}

\author{
Konstantin Krasnoshchekov ${ }^{1}{ }^{*}$ Oleg Yakubailik ${ }^{2}$ \\ ${ }^{1}$ FRS Ksc SB RAS, Krasnoyarsk, Russia \\ ${ }^{2}$ Institute of Computational Modeling SB RAS, Krasnoyarsk, Russia
}

\begin{abstract}
The work compared the data on ground-based concentrations of suspended particles $\left(\mathrm{PM}_{2.5}\right.$ (particulate matter with diameters less than 2.5 microns) and $\mathrm{NO}_{2}$ (sulfur dioxide)) with remote sensing data obtained over the territory of Krasnoyarsk in the summer period of 2019 and 2020. We use the air monitoring system of the Krasnoyarsk Scientific Center of the Siberian Branch of the Russian Academy of Sciences (KSC SB RAS) to determine the concentration of PM 2.5. $\mathrm{NO}_{2}$ concentrations were taken from the data of the State departmental information and analytical system of data on the state of the Ministry of Ecology of the region. It is shown that the data of the MAIAC product, which has a spatial resolution of $1 \mathrm{~km}$, can be used to determine the $\mathrm{PM}_{2.5}$ concentration as a supplement to the data obtained by the ground-based air monitoring system of the KSC SB RAS. A high coefficient of determination between satellite and ground monitoring data was obtained. Joint processing of data from ground-based monitoring networks with remote sensing data will contribute to improving the assessment of the ecological situation in Krasnoyarsk.
\end{abstract}

\section{Introduction}

The low quality of atmospheric air affects the health of the population and the state of the environment in general. Consequently, the issue of assessing air quality is especially acute in large industrial and developing cities. PM of natural or anthropogenic origin have a significant impact on the climate, the environment and have a negative impact on human health. [1]. Numerous studies have linked an increase in PM concentration with an increase in the number of deaths and an increase in respiratory diseases [2,3].

Toxicology studies [4] have shown that particulate matter $10 \mu \mathrm{m}\left(\mathrm{PM}_{10}\right)$ or less has the ability to enter the bloodstream through the lungs, thereby having a negative impact on health. Therefore, air quality assessment, especially in terms of $\mathrm{PM}_{10}$ and $\mathrm{PM}_{2.5}$, is a pressing issue at the moment.

Nitrogen dioxide $\left(\mathrm{NO}_{2}\right)$, like $\mathrm{PM}$, has a negative effect on the body. The main sources of $\mathrm{NO}_{2}$ are vehicle exhaust gases, emissions from thermal power plants, solid waste incineration, and gas combustion. When a small concentration of nitrogen dioxide enters the respiratory system, a person experiences respiratory failure, coughing, an increase in concentration can lead to oxygen starvation and other negative consequences.

\footnotetext{
*Corresponding author: krasko@icm.krasn.ru
} 


\section{Data and measurements}

\subsection{Study area}

The city of Krasnoyarsk is the regional center of the Krasnoyarsk Territory, with a population of more than 1 million people. It is actively developing and has an area of about $350 \mathrm{~km}^{2}$. The coordinates of the city center are $56^{\circ} 00^{\prime}$ north latitude and $92^{\circ} 52^{\prime}$ ' east longitude. The city and the surrounding territories have a unique relief. From the south and west of the city, there are forests and hilly terrain. From the north and east, the terrain is mostly flat. The Yenisei River, which does not freeze in winter due to the nearby Krasnoyarsk hydroelectric power station, divides the city approximately in half. Like all major cities, Krasnoyarsk is subject to a negative impact on the environmental situation. Motor transport, the private sector, thermal power plants, large enterprises of the metallurgical, machinebuilding, and chemical industries contribute many emissions into the atmosphere and negatively affect the quality of the surrounding air. The concentration of $\mathrm{PM}_{2.5}$ in Krasnoyarsk is $64 \%$ higher than the average in Russia [5].

\subsection{Satellite data}

To determine the PM concentration using satellite-sensing data, the AOD (aerosol optical depth) parameter is usually used [6]. AOD is the integrated atmospheric dispersion of radiation by aerosols in a vertical column of the atmosphere. This parameter is proportional to the number of particles in the air and depends on their mass concentration.

In our work, we used the data of the MAIAC product. It has a spatial resolution of $1 \mathrm{~km}$. The MCD19A2 (MAIAC) product contains data from the MODIS spectrophotometer installed on the Terra and Aqua satellites. This product was published on May 30, 2018 and contains AOD data from February 1, 2000 [7].

Since data on AOD are available only in the absence of snow cover [7], the period from June to August 2019 and 2020 was taken, a total of 184 days. However, the AOD data is also limited by the presence of cloud cover. As a result, the final number of days used in the calculations was 80 .

We used the product OMNO2d as satellite data on nitrogen dioxide. This product provides data for $\mathrm{NO}_{2}$ in a vertical column of the atmosphere with a spatial resolution of 0.25 by 0.25 degrees. The OMNO2d product contains daily $\mathrm{NO}_{2}$ values for the entire territory of the Earth from October 1, 2004 to the present [8].

\subsection{Ground data}

The data on $\mathrm{PM}_{2.5}$ of the air monitoring system of the Krasnoyarsk Scientific Center, consisting of 26 monitoring posts, were used in work. A certified CityAir air monitoring station developed by a group of companies from the Novosibirsk Technopark and the Skolkovo Innovation Center is installed at each monitoring post. These stations provide information about the state of the surrounding air, its temperature, pressure, and humidity. Additionally, an optical sensor is installed inside the station to measure the concentrations of $\mathrm{PM}_{2.5}$ and $\mathrm{PM}_{10}$. Data on $\mathrm{NO}_{2}$ were obtained from the State regional environmental departmental information and analytical data system of the Krasnoyarsk Territory. There are 7 automated observation posts (AOP) installed on the territory of Krasnoyarsk, providing information on the concentrations of carbon monoxide, sulfur dioxide, nitrogen dioxide, hydrogen sulfide, and other pollutants. For our study, we used data from two AOPs since data from other AOP had gaps in the study period. 


\section{4 $\mathrm{PM}_{2.5}$ estimation based on satellite data}

We have calculated the correlation coefficient between remote sensing data and ground data. Remote sensing data (AOD) has been pre-processed and converted to PM values using formula 1. Based on the value of the calculated correlation coefficient, it is possible to estimate the extent to which satellite monitoring data can be used to assess the environmental situation in the city. For comparison, we took the AOD data located above the ground monitoring station, as shown in figure 1 . Then, the obtained values were averaged, obtaining the average value over the city.

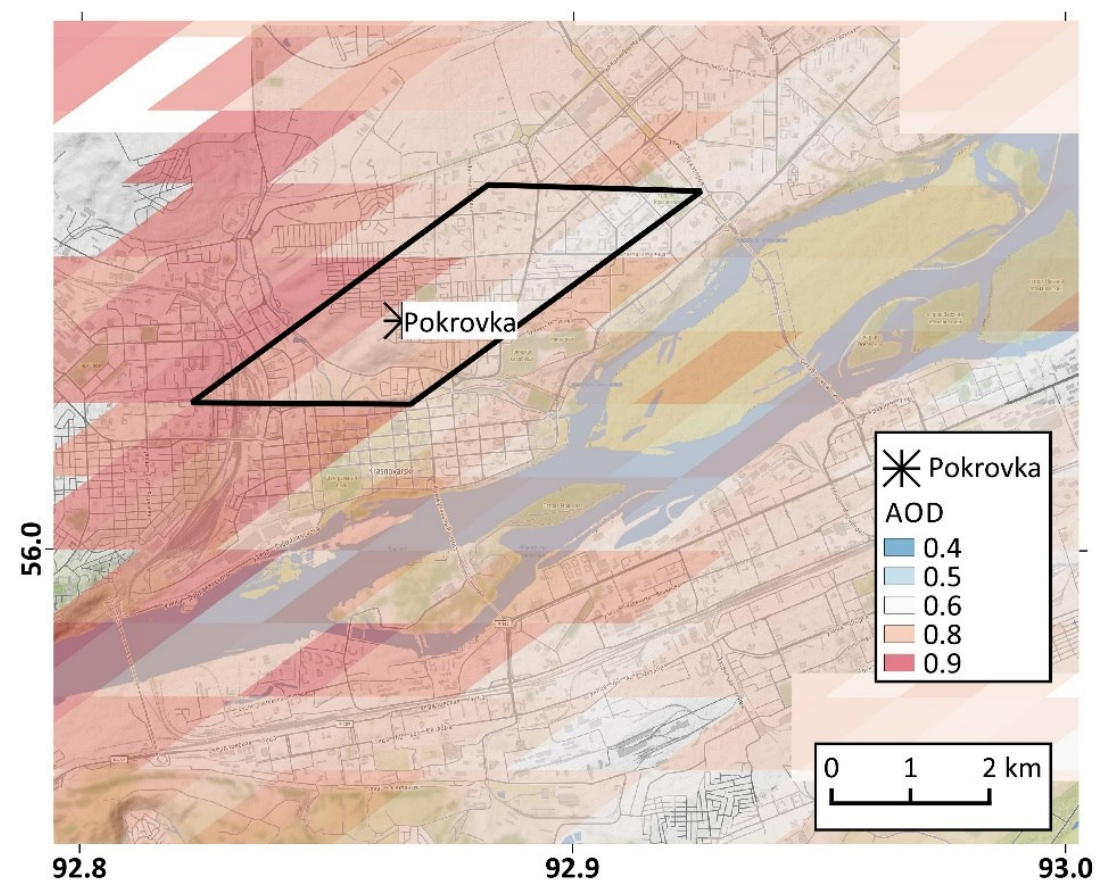

Fig. 1. The area of averaging AOD values above the "Pokrovka" monitoring station.

The data averaging area in figure 1 is shown with a black frame. This area for each station is 3 by 3 pixels ( 3 by 3 kilometers). This is necessary in order to reduce the amount of missing data. Ground-based monitoring data were taken as the average value of PM2.5 concentration, measured in the period from 12:00 to 13:00 noon, then the data between the posts were averaged to obtain the average $\mathrm{PM}_{2.5}$ value in the city.

To compare the AOD and $\mathrm{PM}_{2.5}$ data, the AOD data were converted to $\mathrm{PM}_{2.5}$ units $(\mu \mathrm{g} /$ $\mathrm{m} 3$ ). We used a model of the kind shown in formula (1). It includes meteorological parameters and takes into account aerosol characteristics. This formula is widely used to compare data on AOD and PM and is described in detail in [5].

$$
P M_{\text {calc }}=(A O D / P B L H) /\{K \cdot[(1-R H) /(1-R H 0)]-\gamma\}
$$

To obtain the calculated values according to the formula (1), it is necessary to take into account, in addition to the AOD values, such parameters as: PBLH - the height of the planetaru boundary layer, RH - air humidity, RHO - the average value of air humidity for the 
selected area, the variables $\gamma$ and $\mathrm{K}$ are aerosol characteristics and they obtained from [8]. The results obtained by formula (2) are shown in figure 2 .

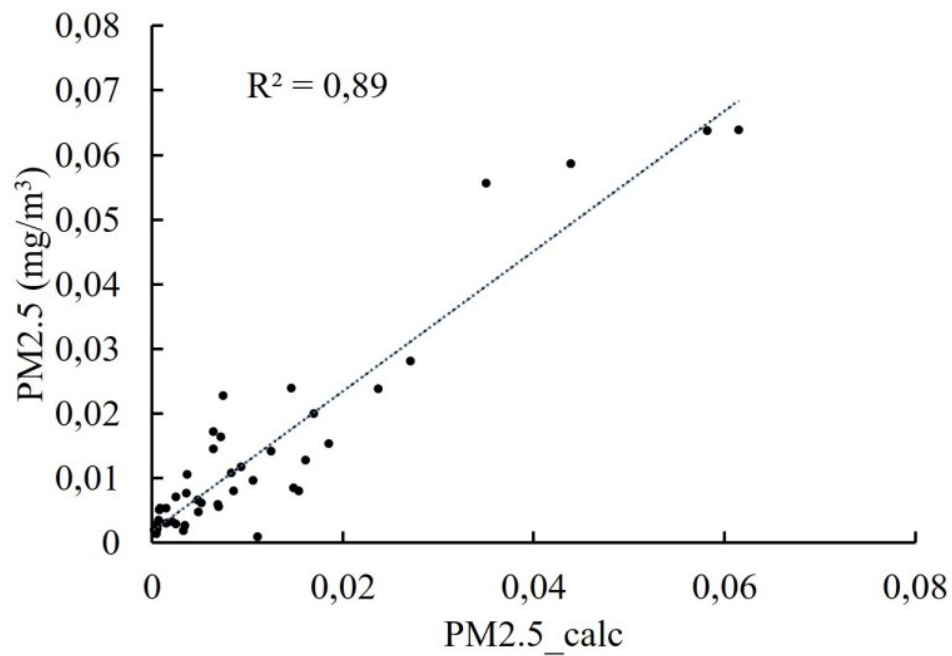

Fig. 2. Comparison of ground data (y-axis) and calculated $\mathrm{PM}_{2.5}$ values calculated by formula 1 (xaxis).

By reducing the satellite monitoring data to the units of measurement obtained at groundbased monitoring stations, the obtained two data series were compared and the coefficient of determination between them was calculated $\left(\mathrm{R}^{2}=0.88\right)$. Such a high value of the coefficient of determination indicates that the PM data calculated using satellite monitoring are in high agreement with the data measured at ground-based monitoring stations.

\section{$2.5 \mathrm{NO}_{2}$ estimation based on satellite data}

In order to assess the extent to which satellite monitoring data can be used to assess the environmental situation in the city by the $\mathrm{NO}_{2}$ parameter, we calculated the correlation coefficient between $\mathrm{NO}_{2}$ data obtained from ground-based observations and $\mathrm{NO}_{2}$ data obtained from satellite monitoring data. Since the data has a spatial resolution of 0.25 by 0.25 degrees, the territory of Krasnoyarsk is covered by two pixels, they were averaged among themselves. For comparison of satellite and ground data, the time period was chosen from June 1 to August 31, 2020. $\mathrm{NO}_{2}$ satellite monitoring data are provided in units of molec $/ \mathrm{cm}^{3}$ in the vertical column of the atmosphere, data from ground-based monitoring stations are provided in units of $\mathrm{mg} / \mathrm{m}^{3}$. To calculate the correlation coefficient between two data series, we transformed the satellite monitoring data series using formula 2

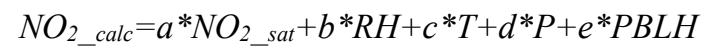

where $\mathrm{NO}_{2}$ sat is $\mathrm{NO}_{2}$ data obtained using the product $\mathrm{OMNO} 2 \mathrm{~d}, \mathrm{RH}$ is air humidity, $\mathrm{T}$ is air temperature, $\mathrm{P}$ is air pressure, PBLH is the height of the atmospheric boundary layer. The results obtained using formula 2 are shown in the figure 3. 


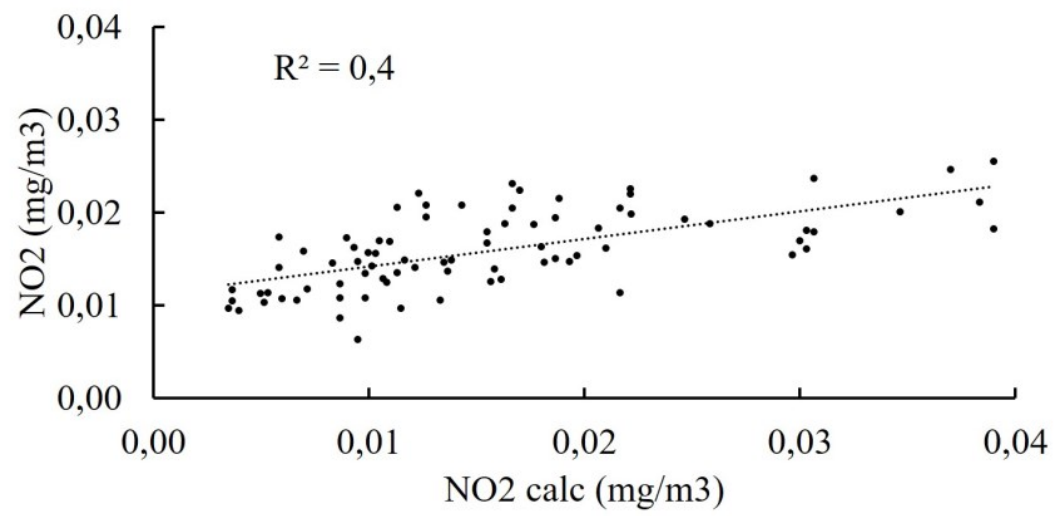

Fig. 3. Comparison of ground data (y-axis) and $\mathrm{NO}_{2}$ values calculated by formula 2 (x-axis).

The value of the coefficient of determination for $\mathrm{NO}_{2}$ is worse than the value for $\mathrm{PM}_{2.5}$, most likely this is due to the coarser spatial resolution of satellite data. However, for the tasks of assessing the impact of the urban environmental situation on the surrounding suburban area, this accuracy is sufficient.

Using satellite monitoring data, it is possible to significantly supplement the data obtained from ground-based monitoring posts, which will enhance the understanding of atmospheric processes occurring in the city and beyond.

\section{References}

1. Y. Kaufman, D. Tanré, O. Boucher, Nature 215-223 (2002)

2.J. Schwartz, F. Laden, A. Zanobetti, Envir. health. perspec. (2002)

3. A. Seaton, D. Godden, W. MacNee, K. Donaldson, The Lancet 345 176-178 (1995)

4. B. Brunekreef, S. Holgate, The Lancet 360 1233-1242 (2002)

5 C. Lin, L. Labzovskii, H. Mak, J. Fung, A. Lau, S. Kenea, M. Bilal, J. Vande Hey, X. Lu, J. Ma, Atmos. Environ. 227 (2020)

6. K. Donaldson, X. Li, W. MacNee, J. Aerosol Sci. 29 553-560 (1998)

7. A. Lyapustin, Y. Wang, S. Korkin, D. Huang, Atmos. Measur. Techniq. 11 5741-5765 (2018)

8. Team O.M.I.N.O.A http://disc.sci.gsfc.nasa.gov/Aura/dataholdings/OMI/documents/v003/OMNO2d_FileSpec 3 (2013) 